\section{GPIAG News}

\section{Respiratory Leaders Programme}

Are you interested in influencing/delivering respiratory care beyond practice level in primary care? Why not consider applying to participate in one or more of our Respiratory Leader Programme Activities...

Respiratory Leaders and PwSI's Initial Development

Workshop

10th-11th July 2009, Wokefield Park, Reading

This event will provide the tools and skills to enable primary care clinicians and nurses with a special interest in respiratory disease to influence and develop specialist services in their primary care region, within the changing NHS environment. Visit our website for more information http://www.gpiag.org/conferences/ resp_leads_2009.php

Respiratory champions and PwSI Update

27th-28th November 2009, Cranage Hall, Manchester

The programme has been designed to provide an update on the changing NHS and an opportunity to debate key clinical and service delivery issues in respiratory medicine. The two days will provide a forum to exchange ideas. Visit our website for more information http://www.gpiag.org/conferences/resp_leads_ 2009.php

Each programme will be delivered by expert speakers, using a series of interactive workshops and presentations. A limited number of places are available FREE OF CHARGE for GPIAG members. Attendance for non-GPIAG members is $f 225$ which includes attendance, dinner and one night's accommodation, plus full membership of the GPIAG for the remainder of 2009.

Attendees will be invited to join GPIAG?the respiratory leaders network, an e-mail group aimed at providing ongoing group support.

\section{Your opportunity to attend the European Respiratory Society (ERS) as part of a Mentorship Programme}

The GPIAG is running the highly successful mentorship programme again in 2009. We are currently seeking three GP candidates to attend the European Respiratory Society Congress on 12th - 16th September 2009 in Vienna. Successful candidates will be offered mentorship throughout the conference and support after the conference to help develop their leadership skills and disseminate learning at a local level.

The candidates will be selected based on the following criteria:
1. Candidates should be a practising GP working in primary care or across the primary /secondary care interface and must be a full member of the GPIAG and/or ARNS

2. Candidates must have a demonstrable record of interest in respiratory medicine such as attendance at one or more national respiratory meetings (e.g., GPIAG, ARNS or BTS), and a diploma or other further education certificate in a respiratory related discipline. Note: preference will be given to those candidates who do not have regular experience of attending major international respiratory conferences.

3. Candidates must be committed to developing as a leader in primary care respiratory medicine i.e. working beyond practice level to influence, develop or deliver respiratory services in (providing written evidence in the form of a CV and short application)

4. Candidates must provide clear aims and objectives for participating in the programme and have a clear commitment to completing the programme including specific evaluation reports.

5. Candidates will be required to provide a letter of support from their practice or PCT in case of GP principal or line manager in other cases

Interested applicants should contact the GPIAG for more information and details on how to apply - please telephone 0121 3514455 or email info@gpiag.org to request application information

\section{GPIAG Conference}

\section{Transforming respiratory care - Your chance to make a difference}

\section{5th-26th September 2009, Warwick University}

The theme for this year's conference is 'transforming respiratory care' and how primary care health professionals can 'make a difference' both through their individual clinical care of patients, and how they structure and organise respiratory care within the practice and beyond.

The programme offers main plenary sessions focusing on asthma, COPD, respiratory related-allergy and how to 'get care right', and parallel sessions including the differential diagnosis of respiratory disease, managing infection, oxygen therapy, and key service delivery issues such as sleep apnoea, how to develop a 'managed clinical network', and the training of health professionals in respiratory medicine. Cutting edge clinical 
research sessions are also available, as well as 'how-to workshops' for those practical issues such as choice of inhaler device, spirometry, or allergy testing. Speakers include leading physicians and primary care experts in the field including Professor Peter Calverley, Dr Tony Davison, Dr John Haughney and Dr David Halpin.

To download the conference brochure, view the programme and for further information on how to register please visit our website at http://www.gpiag.org/conferences/index.php

\section{SPECIAL OFFER FOR NURSE AND GP TO ATTEND FROM THE SAME PRACTICE}

The GPIAG are delighted to offer a specially-reduced registration package for a nurse and GP to attend from the same practice. Visit our website for more information - http://www.gpiag.org/ conferences/registration.php

\section{IPCRG News}

\section{Research}

The IPCRG is one of 41 partners across Europe participating in the U-BIOPRED study led by Dr Peter Sterk (Unbiased BIOmarkers used for PREDicting disease progression and medication efficacy in severe asthma) that has just been selected for funding by the European Union Innovative Medicines Initiative. Our role is in Ethics \& Safety and Dissemination. See http://www.fp7consulting.be/en/news/2009/03/26/u-biopred-proposal-selectedfor-funding/

The IPCRG'S UK Respiratory Research Foundation is funding The TAKL Study: An Investigation of the Safety and Efficacy of Oral AKL1 in Patients Diagnosed with Obstructive Lung Disease. This is a Phase II trial led by Dr Andrew Wilson of the University of East Anglia. It is an extension of the DDX trial in asthma previously undertaken by Dr Mike Thomas at Aberdeen University.

The pilot of FRESH AIR has begun in Vietnam due to the tremendous enthusiasm and hard work of our Vietnamese colleagues, Prof Lan, Dr Vinh and Dr An facilitated by members of the IPCRG e-faculty - Niels Chavannes, David Price and Alan Crockett. FRESH AIR is investigating the effectiveness of casefinding and indoor air pollution-reduction strategies in resource- limited primary care settings. The team is also doing qualitative work into smoke-related beliefs and validating questionnaires for use in different Vietnamese settings.

Meet the Vietnamese team and others at the IPCRG Scientific Conference, Stansted on 4th-5th June. See http://www. theipcrg.org/sci_conf_2009/

\section{Education}

Many IPCRG members ran events for World Asthma Day, including free spirometry testing in Cyprus, Vietnam and India; public awareness campaigns using national media in Pakistan, Cyprus and Australia, and the inauguration of diploma level education in Bangladesh. For further details please see http://www. theipcrg.org/campaigns/wad_2009_intro.php

Thanks to the work of Svein Henrichsen and Jim Reid, the IPCRG (which is a Special Interest Group of Wonca Europe) will run a workshop at the Wonca Europe Conference in Basel 16-19 September: People with asthma who smoke /Smoking cessation in a busy practice.

With colleagues from the Hellenic Primary Care Respiratory Group, Jim Reid will be representing the IPCRG at the 9th Wonca Rural Health World 2009 Conference, 12-14 June 2009, Heraklion, Crete, Greece, delivering a workshop entitled Chronic Obstructive Pulmonary Disease - A Doctor's Heartsink?

We are partnering our newest associate member, the International COPD Coalition (ICC) at its first world conference of COPD patients in Rome in 14 June. For more information see http://www.internationalcopd.org/Conference/Default.aspx. David Price will represent us.

Osman Yusuf, Dermot Ryan and David Price led sessions at the recent and First Middle East-Asia Allergy Asthma and Immunology conference in Dubai March 26-29.

\section{External Affairs}

Niels Chavannes will represent the IPCRG at the 2009 General Meeting of the Global Alliance against Chronic Respiratory Diseases (GARD) which will be held in Rome, Italy on 12-13 June 2009. See http://www.who.int/gard/en/.

Siân Williams, Executive Officer 